\title{
Study of Corporative Knowledge Administration in the System of Business Continuity Management
}

\author{
Likhacheva L.B.* \\ Voronezh State University of Engineering Technologies \\ Voronezh, Russia \\ e-mail: lbmila@ya.ru
}

Zemskov Y.P.

Voronezh State University of Engineering Technologies

Voronezh, Russia

e-mail: regant2006@mail.ru

\author{
Nazina L.I. \\ Voronezh State University of Engineering Technologies \\ Voronezh, Russia \\ e-mail: nazina_lyudmila@mail.ru \\ Matveeva E.V. \\ Voronezh State University of Engineering Technologies \\ Voronezh, Russia \\ e-mail: katrin_vgta@mail.ru
}

\begin{abstract}
In modern conditions of the economic formation there is a necessity of transforming the intellectual knowledge to the corporative knowledge - a system of accumulation and transmission of technological, production, organizational, functional, business and other information with the aim of the company's development and upgrading. The introduction of business continuity principles may be directed on raising the efficiency of the organization's activity and attracting new consumers. Versatile company's upgrading of business processes and elimination of weak points (risks) leads to financial advantages, time and resources reduction. The realization of management on the basis of business continuity principles needs to determine the most important, key indices of the processes, to fix action algorithms, dates and executives responsible for the implementation of definite arrangements. It is required to analyze the statistical data of the process functioning, probability of risks emergence and their after-effect weights and develop a plan to reduce possible negative impacts. Such is the process of constant upgrading of business processes with the use of methods and principles of risks management, on the example of the process "Ideas and offers management". The suggested solution will enable to effectively implement and upgrade the business process "Ideas and offers management" of organizations of different sizes and kinds of activities. The practical value of the suggested methodology is in the fact that application of risks management methods in the process of "Ideas and offers management" will make it possible to realize the up grading of the corporative culture, will motivate the executives to exchange opinions and knowledge, which will enlarge the framework of simple information structuring and facilitate the access to it for persons concerned.
\end{abstract}

Keywords - business continuity management, risks analysis, knowledge and ideas management.

\section{INTRODUCTION}

In modern conditions of the economic formation there is a necessity of transforming the intellectual knowledge into the corporative knowledge - a system of accumulation and transmission of technological, production, organizational, functional, business and other information with the aim of the company's development and upgrading.

To provide business continuity [1] the companies' management makes use of various instruments and practices which include: lean production (a conception of economical production), benchmarking, best practice application, a system of balanced indices, etc.

The work to create the system of business continuity management (BCM) favors the development of the organizational culture in the following spheres:

- organization personnel involvement;

- distribution of duties and responsibilities;

- measurement on the basis of process functioning indices;

- enhance the notification;

- practical training; etc.

The organization must determine, plan, realize and function in accordance with the legal and obligatory requirements, demands of the sides interested in increasing the business competitiveness.

The organization's work efficiency may be determined, in particular, by its ability to use and develop knowledge, transform it into innovative products and services, anticipating customers' needs. Any company's key necessity in contemporary conditions is the ability of effective provision of knowledge transmission from one executive to another, constantly making up the deficiency, transforming knowledge into the most important factor of productive system alongside with other resources.

The problem of corporative knowledge management is widely elucidated in literature [2] and to the present time a classification of knowledge is devised with the focus on obvious (formalized) and non-obvious (hidden).

By obvious knowledge is meant something that can be described by means of words, symbols, what is easily systematized and transferred. Non-obvious (hidden) knowledge is connected with the worker's experience and actions. Its formation depends on his personal characteristics, emotional state and life values. 
The creation of the system of knowledge [3, 4] as a certain succession of transforming hidden knowledge into obvious and vice versa forms a "knowledge spiral". Following this method enables to reach definite results in accumulating and transmitting the information and knowledge on different levels of management, automatic upgrading of business-processes.

Corporative knowledge comprises several categories: business-processes knowledge, corporative culture knowledge, technological knowledge, knowledgeof environment and personal knowledge of executives.

The organization's task is to reveal non-obvious knowledge, spread it among executives for reaching strategic and tactic organizational aims. Underestimating the role of knowledge management process can result in problems of organization's functioning, as the increase of intellectual capital is interconnected with the rise of competitiveness of

$\begin{array}{cc}\text { Executives' } & \begin{array}{c}\text { Appointing of } \\ \text { involment }\end{array} \\ \text { experts for the } \\ \text { offerrs' estimation }\end{array}$

science-consuming processes, the number of new clients, ready to purchase the new product.

\section{METHODS AND MATERIALS}

One of the actual ways of raising the processes' effectiveness, increasing the satisfaction of inside and outside consumers on the basis of hidden knowledge revealing is in implementation of the system of submitting executives' offers for improvement. The important task of this system is knowledge management, changing behavior and thinking of the workers, working out a system of motivation. For better convenience and understanding we'll use the notion «business-process "Ideas and suggestions management"».

The business-process "Ideas and offers management" is a formalized process, comprising stages, shown in figure 1 .

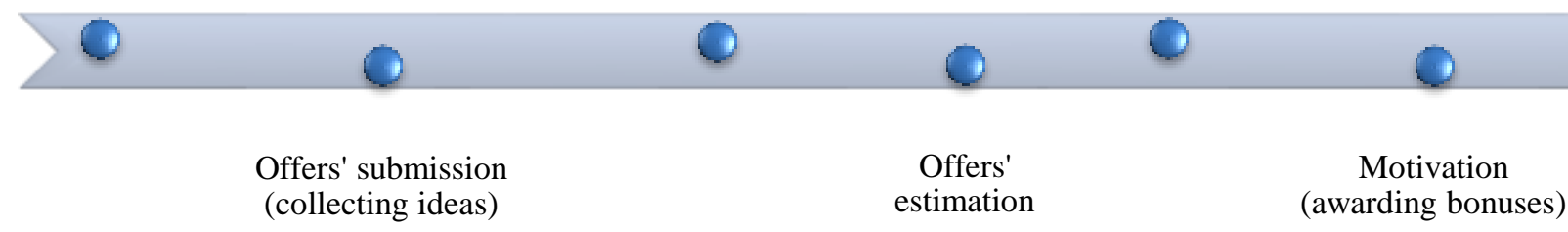

Fig. 1. Stages of the business-process "Ideas and offers management".

On the first stage the executives' involvement is carried out and then follows the collection of offers (ideas). After this the appointment of the expert group for the offers' estimation is accomplished. Having formed "the ideas" portfolio" the members of the expert group estimate the submitted offers, decline "non-viable", approve acceptable and finish off good offers. At the next stage the approved offers are implemented and distinguished workers are given conformable financial awards. The executives' offers may concern improvement of labor organization and working conditions, increase of labor productivity, preventive measures in ecology and ways to reduce negative effects on the environment, minimization of the losses, improvement of goods quality and so on.The offers may be connected with such modern methods of quality management as lean production, 5s (regulating), TPM (total production maintenance), risks management, etc.

All the mentioned actions affect the activity of the whole organization, are important components of quality management and safety of the organization's activity results.

The outcomes of the process "Ideas and offers management" introduce other processes, such as marketing, working out of construction and technological documentation, purchases, production, sales, service, quality management and others $[5,6]$. The mechanism of such interconnection is shown in fig. 2.

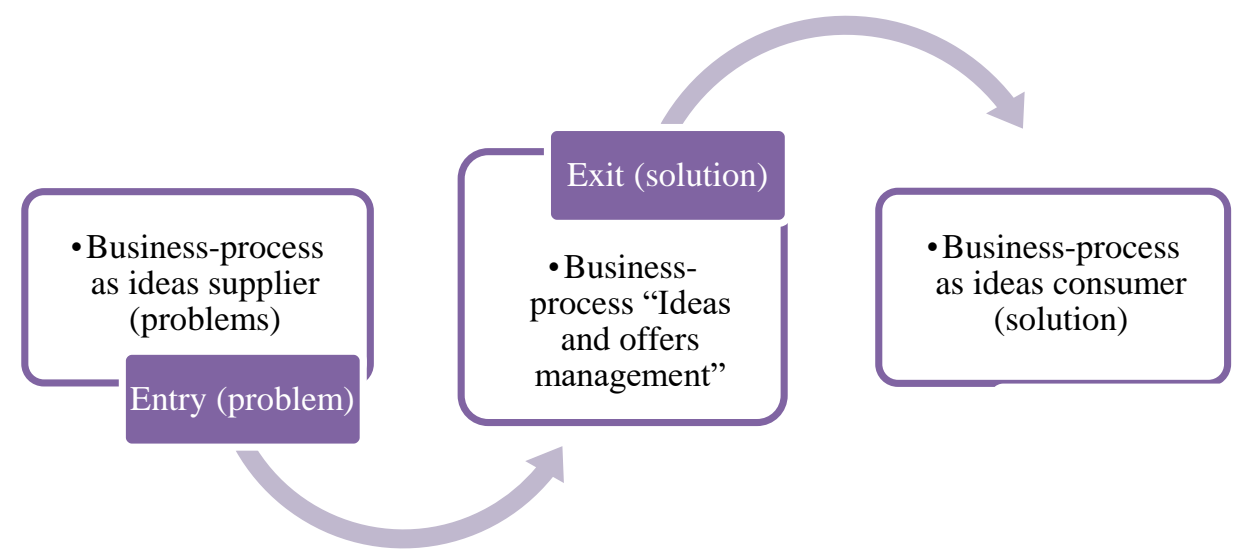


Fig. 2. Interconnection mechanism of th eprocess "Ideas and offers management"

\section{RESULTS}

The described business-process demands attention from the superior management, elaboration of a plan of arrangements that presuppose avoiding of potential mistakes and their impact on the organization's activity [7]. In order to achieve the indicated task the risks management process is applied, that includes identification of possible threats for creating the basis of the company's stability upgradingand defense of the key interests of the sides concerned. The risks for the process "Ideas and offers management" may be considered as an algorithm, given below:

a) designing a decomposition of the process with the view of potential threats that can emerge at every stage;

b) determination of the factors influencing the process from the point of view of different participants of the process (the author, the expert, the process manager, the organization supervisor, the owner of the process - the offer's consumer);

c) the degree of the process' correspondence to the stated requirements (the way the process is manageable, controlled and effective);

d) interconnections with other processes in the organization (part of the entry processes are exits of other processes in which it is necessary to look for the sources of problems);

The risk management allows giving a complex estimation of threats and possibilities, connected with the process in view, and work out measures to decrease the risk degree. The principle of application of the risk management conception for the implementation of the business-process "Ideas and offers management" is presented as a consequence of actions given in fig. 3 .

At the stage of the goal determination the choice of the most significant of all goals and tasks is realized, which can be interconnected with the choice of the personnel motivation method, designing measures to reduce the costs of production, raise of labor productivity, increase of the product competitiveness, corporative culture formation.

If we consider the implementation stage of the businessprocess "Ideas and offers management" we note, that the main goal is to involve the company's executives in the activity of constant improvement. Determination of the process stages is carried out with formalization of all stages, stating the life cycle, noting the process' owner and every stage content [8-10].

Then, with the help of the expert method possible risks (threats) connected with the process goal are determined. Leading specialists of adjacent tactical and administrative departments are enlisted to cooperation as experts.

At the next stage the risk significance estimation is carried out for the criteria "possibility of emergence - gravity of consequences".

Then, suitable methods of risks management are chosen, the method of choosing objective proofs is stated.

The stage of the plan of measures elaboration includes actions to reduce or exclude risks influence on the process and the system of administration as a whole.Then comes the time to realize the developed plan to reduce the most significant risks.Sometimes these actions are sufficient to lower the influence of less significant risks.

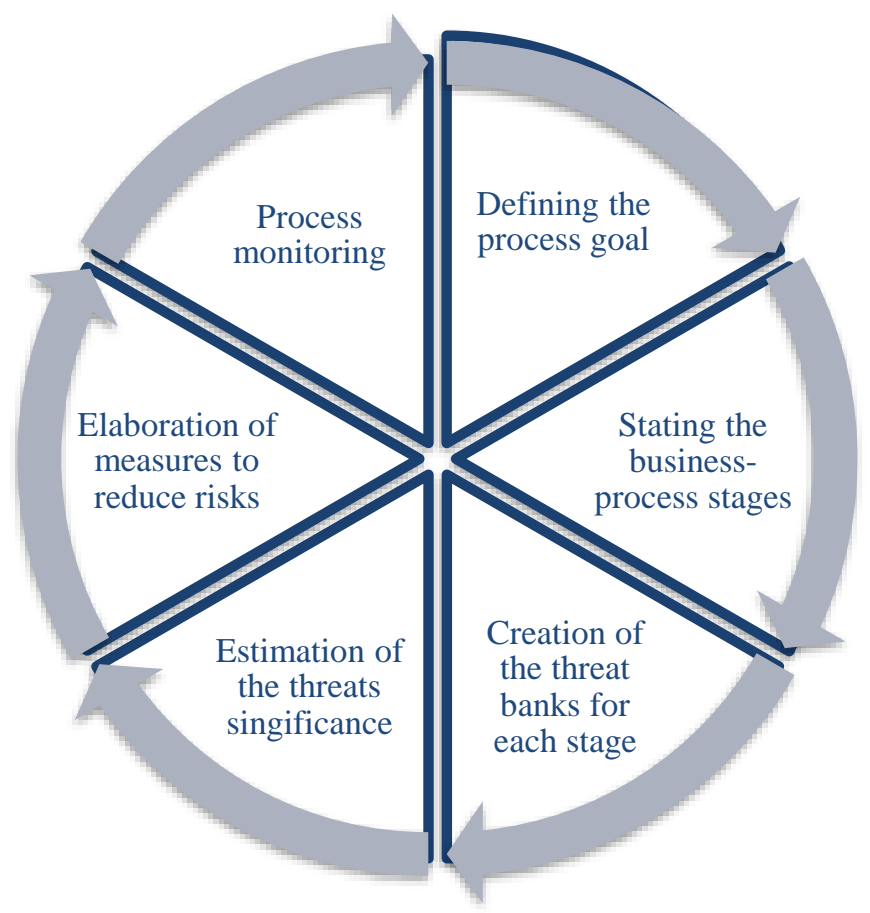


Fig. 3. System of the risks' analysis.

The algorithm of actions is repeated after fulfilling the plan of measures to eliminate the risks.

The risk-management theory considers risks from the position of divergence of actual results of activity from nonplanned. In connection with the uncertainty of the inside environment of the organization events occur leading to negative consequences that are called risks.

The results or risk estimation at every stage of the process are shown in table 1 .

TABLE I. RISKS ESTIMATION RESULTS AT THE STAGES OF THE PROCESS "IDEAS AND OFFERS MANAGEMENT",

\begin{tabular}{|c|c|c|c|c|c|}
\hline 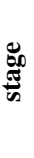 & Stage title & $\begin{array}{l}\text { Risksthatcanem } \\
\text { ergeateverystage }\end{array}$ & $\begin{array}{c}\text { Risk } \\
\text { emergence } \\
\text { probability }\end{array}$ & $\begin{array}{c}\text { Conse } \\
\text { quence } \\
\text { gravity }\end{array}$ & 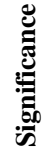 \\
\hline 1 & $\begin{array}{l}\text { Executives' } \\
\text { involvement } \\
\text { into the } \\
\text { upgrading } \\
\text { activity }\end{array}$ & $\begin{array}{l}\text { The executives } \\
\text { won't take an } \\
\text { active part in the } \\
\text { offer submitting } \\
\text { program. }\end{array}$ & $\begin{array}{l}\text { Most } \\
\text { probable } \\
(4)\end{array}$ & $\begin{array}{l}\text { Consid } \\
\text { erable } \\
(3)\end{array}$ & 12 \\
\hline 2 & $\begin{array}{l}\text { Offer } \\
\text { submitting }\end{array}$ & $\begin{array}{l}\text { The executives' } \\
\text { offers do not } \\
\text { correspond to the } \\
\text { goals of business } \\
\text { and } \\
\text { administration's } \\
\text { expectations }\end{array}$ & $\begin{array}{l}\text { Probable } \\
\text { (3) }\end{array}$ & $\begin{array}{l}\text { Consid } \\
\text { erable } \\
\text { (3) }\end{array}$ & 9 \\
\hline 3 & $\begin{array}{l}\text { Expert } \\
\text { appointment }\end{array}$ & $\begin{array}{l}\text { The offer is } \\
\text { estimated by a } \\
\text { non-adequate } \\
\text { expert }\end{array}$ & $\begin{array}{l}\text { Probable } \\
\text { (3) }\end{array}$ & $\begin{array}{l}\text { Mediu } \\
\text { m level } \\
(2)\end{array}$ & 6 \\
\hline 4 & $\begin{array}{l}\text { Offer's } \\
\text { implementati } \\
\text { on }\end{array}$ & $\begin{array}{l}\text { The offer is not } \\
\text { implemented or } \\
\text { implemented } \\
\text { with time delay }\end{array}$ & $\begin{array}{l}\text { Probable } \\
\text { (3) }\end{array}$ & $\begin{array}{l}\text { Mediu } \\
\text { m level } \\
(2)\end{array}$ & 6 \\
\hline 5 & $\begin{array}{l}\text { Offer } \\
\text { estimation }\end{array}$ & $\begin{array}{l}\text { The offer's } \\
\text { estimation is not } \\
\text { correct }\end{array}$ & $\begin{array}{l}\text { Hardly } \\
\text { probable } \\
(2)\end{array}$ & $\begin{array}{l}\text { Insigni } \\
\text { ficant } \\
\text { (1) }\end{array}$ & 2 \\
\hline 6 & Motivation & $\begin{array}{l}\text { The deserved } \\
\text { bonus is not paid }\end{array}$ & Rarely (1) & $\begin{array}{l}\text { Insigni } \\
\text { ficant } \\
\text { (1) }\end{array}$ & 1 \\
\hline
\end{tabular}

To reveal the most significant risks we'll make use of Pareto diagram (fig. 4) and compile a risk level map (fig. 5).

According to Pareto rule, the most significant risks are: executives' involvement in the upgrading activity, offer submitting, expert appointment.

The risk map has enabled to reveal and estimate potential risks capable of rendering a negative inpact on the process in view. Risks 1-4 are in the zone of inadmissible risk (red on the diagram), in connection with this fact there is a necessity to elaborate a plan for managing and upgrading the process. Risk groups in the red zone demanda plan of immediate measures, risk groups in the yellow zone need a plan of controllable measures in order to transfer these risks in the category of inadmissible. Thus the key divergences in the process can be the two mentioned factors, that are capable of leading to the unattainability of planned results for the process. To the measures of reducing the riskfort he process "Ideas and offers management" belong:

a) carry in gout promo-actions for promoting the program (to determine periodicity and methods);

b) determine indices which will be used to trace the program efficiency results, methods of information collecting and persons responsible for information supply and data processing;

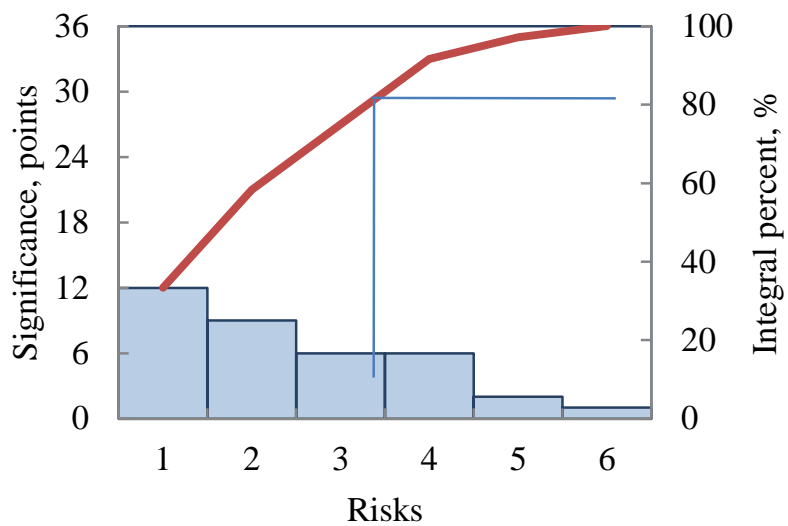

1. Executives' involvement in to the upgrading activity.

2. Offer submitting. 3. Expert appointment.4. Offer implementation.

5. Offer estimation. 6. Motivation.

Fig. 4. Pareto diagram for choosing the most significant risk.

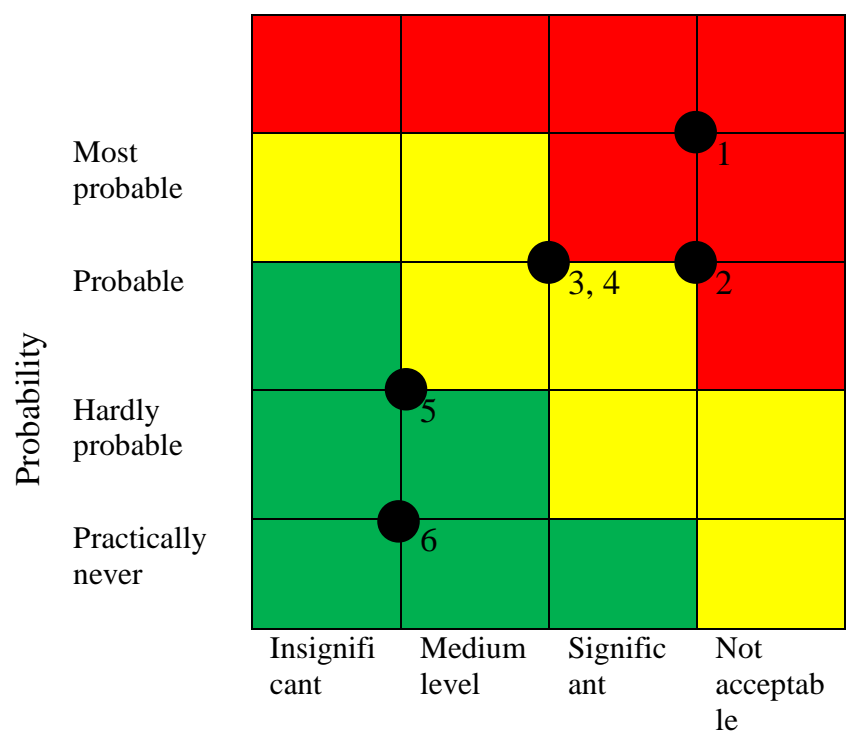

Consequence gravity

1. The executives won't take an active part in the offer submitting program. 2 The executives' offers do not correspond to the goals of business and administration's expectations. 3. The offer is estimated by a non-adequate expert. 4. The offer is not implemented or implemented with a big delay of 
time. 5. The offer's estimation is not correct. 6. The deserved bonus is not paid.

Fig. 5. Risks level map.

c) organization of regular meetings of superior managers and department supervisors for discussion of results.

d) define requirements for offers;

e) state the problems for offers, single out the most acute.

f) compile a list of experts and suggest a circle of offer subjects which can be estimated by certain experts;

g) carrying out regular meetings with certain experts for discussing questions of cooperation in the program;

h) control for offers implementation on the part of superior management (assistance for the experts, allocation of conformable resources);

i) envisage the means of inverse connection from the expert to the author;

j) envisage the process of information transmission to the personnel department.

\section{CONCLUSION}

To increase the organization's competitiveness it should demonstrate to the potential consumers its ability to supply the goods in conditions of outer environment uncertainty. Implementation of the requirements of business continuity management may be directed on raising the effectiveness of the organization's activity and attracting new consumers. Versatile upgrading of the organization's business-processes and elimination of weak points (risks) lead to receiving financial profits, decrease of losses of time and resources.

To realize management on the basis of business continuity principles it is necessary to determine the most important, key indices of the processes, define the algorithm of actions, dates and executives responsible for the implementation of certain measures. It is necessary to analyze statistic data on the process functioning, probability of risks emergence and gravity of their consequences and elaborate a plan of measures for their decrease.

That is the essence of the process of constant upgrading of business-processes with the use of methods and principles of risks management on the example of the process "Ideas and offers management”.

The suggested solution will enable to effectively implement and upgrade the business process "Ideas and offers management" of organizations of different sizes and kinds of activities. The practical value of the suggested methodology is in the fact that application of risks management methods in the process of "Ideas and offers management" will make it possible to realize the upgrading of the corporative culture, will motivate the executives to exchange opinions and knowledge, which will enlarge the framework of simple information structuring and facilitate the access to it for persons concerned.

\section{References}

[1] I.A. Kiseleva, N.E. Simonovich, E.D. Solomatina, "Social well-being of people and the strategy of innovative development of the enterprise", Proc. of the Voronezh State Univer. of Engineer. Technol., vol. 81, no. 1, pp. 402-411, 2019.

[2] N.N. Kudryavtseva, Y.V. Pakhomova, Y.N. Duvanova," The concept of management development management enterprise", Proc. of the Voronezh State Univer. of Engineer. Technol., vol. 81, no. 1, pp. 429-433, 2019.

[3] L.B. Likhacheva, N.V. Shevtsova, "Development of indicators to assess the performance of the system for submission of proposals for improvements from employees", Proc. of the Voronezh State Univer. of Engineer. Technol., no. 1, pp. 249-253, 2016.

[4] G.V. Popov, L.I. Nazina, L.B. Likhacheva, S.V. Elizaryev, "The development of the module system of training in the organization", Proc. of the Voronezh State Univer. of Engineer. Technol., no. 4, pp. 137-141, 2012 .

[5] J. Liebowitz, Building organizational intelligence, A knowledge management primer. CRC press, 2019

[6] B. Gunjal, "Knowledge management: why do we need it for corporates", Malaysian J. of Library \& Inform. Sci., 2019. ISSN: 1394-6234.

[7] A. Gábor et al., Corporate knowledge discovery and organizational learning: the role, importance, and application of semantic business process management - the ProKEX case, Corporate Knowledge Discovery and Organizational Learning. Springer, Cham, 2016, pp. 1-31.

[8] I. Soukal, A. Bartuskova, "Design Proposal of the Corporate Knowledge Management System”, pp. 63-72, 2017 [Int. Conf. on Computational Collective Intelligence]. Springer, Cham.

[9] M. Y Del Giudice, M.R. Della Peruta, "The impact of IT-based knowledge management systems on internal venturing and innovation: a structural equation modeling approach to corporate performance". J. of Knowledge Manag., 2016.

[10] A.A. Sezgin, E. İplik, From Personal Knowledge Management to Corporate Knowledge Management, Social Media for Knowledge Management Applications in Modern Organizations. IGI Global, 2018, pp. 169-189. 